\title{
Synergetic Effect of Ni and Au Nanoparticles Synthesized on Titania Particles for Efficient Photocatalytic Hydrogen Production
}

Ana L. Luna, ${ }^{1}$ Ekaterina Novoseltceva, ${ }^{1}$ Essyllt Louarn, ${ }^{1}$ Patricia Beaunier, ${ }^{2}$ Ewa Kowalska, ${ }^{3}$ Bunsho Ohtani, ${ }^{3}$ Miguel A. Valenzuela, ${ }^{4}$ Hynd Remita, ${ }^{1,5}$, Christophe Colbeau-Justin ${ }^{1, *}$

${ }^{1}$ Laboratoire de Chimie Physique, CNRS UMR 8000, Univ Paris-Sud - Université Paris-Saclay, 91405 Orsay, France

${ }^{2}$ Sorbonne Universités, UPMC Univ. Paris 06, UMR 7197-CNRS, Laboratoire de Réactivité de Surface, F-75005 Paris, France

${ }^{3}$ Institute for Catalysis, Hokkaido University, North 21, West 10, Sapporo 001-0021, Japan

${ }^{4}$ Laboratorio de Catálisis y Materiales. ESIQIE-Instituto Politécnico Nacional. Zacatenco, 07738 CDMX, México

${ }^{5}$ CNRS, Laboratoire de Chimie Physique, UMR 8000, 91405 Orsay, France

*Corresponding authors.

E-mail addresses: $\underline{\text { hynd.remita@u-psud.fr and christophe.colbeau-justin@u-psud.fr }}$ 


\begin{abstract}
$\mathrm{Au}$ and/or Ni nanoparticles were synthesized by radiolysis on $\mathrm{TiO}_{2}$ (commercial P25) at various composition (metal content). The modified photocatalysts were characterized by High Resolution Transmission Microscopy (HRTEM), Energy-Dispersive X-ray Spectroscopy (EDS), UV-Vis Diffuse Reflectance Spectroscopy (DRS) and X-Ray Photoelectron Spectroscopy (XPS). The charge-carrier mobility was studied by Time Resolved Microwave Conductivity (TRMC). The photocatalytic activities were tested under UV-visible irradiation using polychromatic and monochromatic light (action spectrum analysis of apparent quantum efficiency). Surface modified $\mathrm{TiO}_{2}$ with $\mathrm{Au}$ and Ni nanoparticles showed high photocatalytic activity for hydrogen evolution from aqueous methanol solution. The enhanced hydrogen evolution rate was obtained for $\mathrm{TiO}_{2}$ co-modified with $\mathrm{Au}$ and $\mathrm{Ni}$, where synergetic effect of the two metals was revealed. A very small amount of gold associated to nickel (atomic ratio Ni:Au 5:1 with a total optimized metal loading of $0.5 \mathrm{at} \%$ ) can induce a significant increase in $\mathrm{H}_{2}$ formation.
\end{abstract}

\title{
Keywords
}

$\mathrm{Ni}: \mathrm{Au} / \mathrm{TiO}_{2}$; Photocatalytic $\mathrm{H}_{2}$ Production; Radiolysis; TRMC; Action Spectra 


\section{Introduction}

Hydrogen is considered as clean energy of the future solving the global energy and environmental crises. Development of efficient and cheap materials for $\mathrm{H}_{2}$ production is a main challenge towards a sustainable hydrogen economy. Nowadays, hydrogen is mostly produced from fossil resources, such as natural gas, oil and coal, which are limited and expensive. Furthermore, hydrogen production from fossil resources has the disadvantage to emit high level of $\mathrm{CO}_{2}$ as a byproduct [1-3]. The recent growing concerns to the global weather changes due to $\mathrm{CO}_{2}$ emissions have encouraged the development of new green and renewable technologies to produce hydrogen. In this context, photocatalysis is a promising method for $\mathrm{H}_{2}$ production as it can use solar energy sustainably and efficiently, and is economically attractive compared to more conventional methods $[3,4]$.

The most widely used semiconductor in photocatalysis is $\mathrm{TiO}_{2}$ because of its physical and chemical properties, excellent stability, high availability and low cost [5]. The photocatalytic process involves photon (of suitable energy: higher or equal to the band gap) excitation of a semiconductor forming an electron-hole pair. The electrons and holes either recombine or migrate to the surface of the semiconductor particle and participate in reduction and oxidation reactions. For $\mathrm{H}_{2}$ production by water splitting, a semiconductor must have a conduction band more negative than the $\mathrm{H}_{2} \mathrm{O} / \mathrm{H}_{2}$ redox couple $(0.0 \mathrm{~V})$ and the valence band more positive than the $\mathrm{O}_{2} / \mathrm{H}_{2} \mathrm{O}$ redox couple (1.23 V versus $\mathrm{NHE}$ ) at $\mathrm{pH}=0$. $\mathrm{TiO}_{2}$ (band gap 3.0-3.3 eV) is probably the most promising semiconductor for $\mathrm{H}_{2}$ production from water or biofuels. However, bare $\mathrm{TiO}_{2}$ is inefficient for $\mathrm{H}_{2}$ generation and it is commonly attributed to high hydrogen overpotential linked to rapid electron-hole recombination, reducing the number of charge-carriers available for the photoreaction. Modification of the $\mathrm{TiO}_{2}$ surface with metal nanoparticles (NPs) of Pt, $\mathrm{Pd}$, or $\mathrm{Au}$ has to be performed to produce hydrogen. According to the conventional explanations, the role of metal is to avoid the recombination of the electron-hole pairs since metal NPs work as an electron sink [6,7]. However, for hydrogen evolution reactions, another function of metal is also expected, i.e., lowering of overpotential of hydrogen evolution, where metal NPs act as a catalyst site for atomic hydrogen $\left(\mathrm{H}^{\bullet}\right)$ formation leading to $\mathrm{H}_{2}$ [8]. Although sacrificial reagents such as methanol, ethanol or glycerol are commonly added to water to scavenge the holes facilitating charge separations, even with hole-scavenging alcohols the efficiency of bare $\mathrm{TiO}_{2}$ to produce $\mathrm{H}_{2}$ 
does not increase, probably due to the above-mentioned high hydrogen overvoltage. Then metal NPs are key components for $\mathrm{H}_{2}$ generation.

The alcohols also serve as additional proton sources for producing $\mathrm{H}_{2}$. Indeed, alcohol oxidation is relatively easier to achieve compared to water oxidation, and photocatalytic $\mathrm{H}_{2}$ production rates in alcohol-water mixtures are about 1-2 orders of magnitude higher than those obtained in pure water.

Many studies have been performed to find the most active metal for photocatalytic $\mathrm{H}_{2}$ production. Several studies have shown that platinum is the most promising metal to enhance the $\mathrm{TiO}_{2}$ photocatalytic activity. The principal inconvenience to use $\mathrm{Pt}$ is its high cost. $\mathrm{Au} / \mathrm{TiO}_{2}$ also displays high activity for $\mathrm{H}_{2}$ generation from alcohol-water mixtures. However, gold is also expensive, and thus it is important to develop efficient and low cost photocatalysts for hydrogen generation. In this context, it has recently been shown that $\mathrm{Ni} / \mathrm{TiO}_{2}$ is a promising system for solar $\mathrm{H}_{2}$ production from an ethanol-water solution $[9,10]$.

Recent studies have demonstrated that deposition of bimetallic NPs on semiconductor surfaces, enhance the photocatalytic performance compared to the monometallic systems [11-13]. Previous investigations have shown that bimetallic catalysts comprising Fe-Ni nanomixtures [14], Pd-Pt cocatalysts [15], Au@Pt core-shell nanocomposites [16] and Au-Ni co-catalysts [17] are examples of synergetic effect in photocatalytic hydrogen production. Particularly, in the photocatalytic system $\mathrm{Au}-\mathrm{NiO} / \mathrm{TiO}_{2}$, it has been found that the addition of $\mathrm{NiO}$ increases hydrogen production compared to the monometallic $\mathrm{Au} / \mathrm{TiO}_{2}$, which was explained in terms of enhancement of the electron (charge) transfer from $\mathrm{TiO}_{2}$ to the $\mathrm{Au}-\mathrm{NiO}$ system and the effect of surface plasmon resonance of gold NPs [17].

Undoubtedly, two key points to ensure a high photocatalytic activity in hydrogen production are the preparation method and the chemical composition of the bimetallic catalysts. Radiolysis is an efficient method to synthesize mono- and bimetallic NPs in solutions and on supports [11,18-21]. Ionizing radiations are currently applied on a large scale for medical and surgery-material sterilization and food decontamination. Development of synthetic protocols for catalytic and photocatalytic materials by radiolysis could thus be transposable to industrial production in the medium term. 
In this work, $\mathrm{TiO}_{2}$ surface was modified with $\mathrm{Ni}$ and/or $\mathrm{Au}$ NPs by radiolysis. The structural characterization, the photocatalytic tests and the study of charge-carrier dynamics were used to explain the improvement in the photocatalytic activity. The apparent quantum efficiency (AQE) of the reaction was measured from 320 to $410 \mathrm{~nm}$ obtaining the action spectrum of the samples. This modification of $\mathrm{TiO}_{2}$ with $\mathrm{Ni}$ and $\mathrm{Au}$ was made to obtain bimetallic NPs with a low amount of expensive noble metal but showing surface plasmon resonance, and to investigate potential synergetic effect of the two metals on the photocatalytic activity.

\section{Experimental}

\subsection{Materials}

Titania P25, Evonik (ca. $50 \mathrm{~m}^{2} \cdot \mathrm{g}^{-1}$, anatase ca. $80 \%$ with rutile) was used as a photocatalyst. Potasium gold (III) chloride (Sigma-Aldrich) and nickel formate (Alfa Aesor) were used as gold and nickel precursors. Methanol and 2-propanol were purchased from Sigma-Adlrich. Deionized water (Milli-Q with 18.6 M $\Omega$ ) was used all through the experiments.

\subsection{Photocatalysts Preparation}

The metal NPs were synthesized on commercial titanium dioxide by the radiolytic method.

For every catalyst, the needed amount of metal precursor was dissolved in $35 \mathrm{~mL}$ of an aqueous solution of 0.2 M 2-propanol (see SI.1). Subsequently, the solutions containing nickel formate were alkalinized with ammonium hydroxide until reaching $\mathrm{pH} 11$. Afterward $1.5 \mathrm{~g}$ of $\mathrm{TiO}_{2}$ was added to each sample. The suspension was stirred $24 \mathrm{~h}$ in order to adsorb the metal ions ( $\mathrm{Ni}^{\mathrm{II}}$ and/or $\mathrm{Au}^{\mathrm{III}}$ ) on $\mathrm{TiO}_{2}$ surface.

After $\mathrm{TiO}_{2}$ surface impregnation, the suspensions were degassed with $\mathrm{N}_{2}$ and then irradiated (under stirring) with a ${ }^{60}$ Co panoramic gamma source (dose rate $=4.5 \mathrm{kGy} \cdot \mathrm{h}^{-1}$ ) $($ SI.1). The metal ions $\left(\mathrm{Au}^{\mathrm{III}}\right.$ and $\left.\mathrm{Ni}^{\mathrm{II}}\right)$ were reduced by solvated electrons and alcohol radicals induced by solvent radiolysis $[18,22]$.

After irradiation, the samples were filtered under vacuum and dried at $30{ }^{\circ} \mathrm{C}$ for $16 \mathrm{~h}$. Finally, colored powders were obtained: grey, purple and pink/violet respectively for nickel, gold and nickel-gold. The tone increases with metal loading. The catalysts were named $x-\mathrm{Ni} / \mathrm{TiO}_{2}, x-$ $\mathrm{Au} / \mathrm{TiO}_{2}$ or $x-\mathrm{NiAu} / \mathrm{TiO}_{2}$ where $x$ means the total metal loading $(0.1,0.5$ and 1 at $\%)$. In the case 
of the bimetallic systems $\mathrm{NiAu} / \mathrm{TiO}_{2}$, the atomic ratio of $\mathrm{Ni}: \mathrm{Au}$ was 5:1. This ratio has been chosen to minimize the amount of noble metal.

\subsection{Catalyst characterization}

UV-Vis Diffuse Reflectance Spectra (DRS) of the photocatalysts were recorded in the region of 200 to 800 nm using an Agilent Technologies Cary 500 with PTFG as reference.

For High Resolution Transmission Electron Microscopy (HRTEM) observations, the suspensions containing modified $\mathrm{TiO}_{2}$ were first sonicated for few minutes, and then a few drops of the suspension were deposited on copper coated carbon grids. HRTEM measurements were performed on a JEOL JEM 2010 transmission electron microscope equipped with a $\mathrm{LaB}_{6}$ filament and operated at $200 \mathrm{kV}$. The chemical analyses were obtained by selected EnergyDispersive X-Ray Spectroscopy (EDS) microanalyser (PGI_IMIX PC) mounted to the microscope.

To realize X-Ray Photoelectron Spectroscopy (XPS) analysis, the powder samples were fixed on double-face adhesive carbon tape mounted on a steel holder. XPS measurements were performed on a K Alpha_X-ray photoelectron spectrometer under ultrahigh vacuum $\left(5 \times 10^{-9} \mathrm{mbar}\right)$. An $\mathrm{Al}$ $\mathrm{K} \alpha(\mathrm{h} v=1486.7 \mathrm{eV})$ monochromated X-ray source operated at $3 \mathrm{~mA}$ corresponding to a spot size of $400 \mu \mathrm{m}$. Survey scans were acquired at a pass energy of $200 \mathrm{eV}$ and $50 \mathrm{eV}$ for the acquisition of high-resolution windows over the binding energy range of $1350-0 \mathrm{eV}$. The $\mathrm{C} 1 \mathrm{~s}$ signal at 284.8 $\mathrm{eV}$ was used as reference to compensate any charging effects.

The charge-carrier lifetimes in bare and modified $\mathrm{TiO}_{2}$ after UV illumination were studied by Time Resolved Microwave Conductivity method (TRMC). For TRMC measurements, the incident microwaves were generated by a Gunn diode of the $\mathrm{K} \alpha$ band at $30 \mathrm{GHz}$. The pulsed light source was an OPO laser (EKSPLA, NT342B) tunable from 225 to $2000 \mathrm{~nm}$. It delivers 8-ns FWMH pulses with a frequency of $10 \mathrm{~Hz}$. The density of light energy received by the sample was

$747 \mu \mathrm{J} . \mathrm{cm}^{-2}$ at $355 \mathrm{~nm}$. To minimize the noise, a TRMC signal is obtained averaging measurements during 200 laser pulses. The reproducibility is controlled by making two TRMC signals on two different samples of the same powder. The TRMC curves presented here are made averaging those two TRMC signals. The estimated relative error on the TRMC value is $5 \%$. 
The TRMC technique is based on the measurement of the relative change of the microwave power reflected by a sample (semiconductor), $\Delta \mathrm{P}(\mathrm{t}) / \mathrm{P}$, during its simultaneous irradiation by a laser pulse. Such relative variation can be correlated to small perturbation of sample conductivity, $\Delta \sigma$, as shown in the following equation:

$$
\Delta \mathrm{P}(\mathrm{t}) / \mathrm{P}=A \Delta \sigma(\mathrm{t})
$$

where $A$ is a time independent proportionality factor. Because the electron mobility, $\mu_{\mathrm{e}}$, in $\mathrm{TiO}_{2}$ is much larger than the hole mobility, $\Delta \sigma(\mathrm{t})$ can be attributed to excess electrons:

$$
A \Delta \sigma(\mathrm{t}) \approx \Delta \mathrm{n}(\mathrm{t}) \mathrm{e} \mu_{\mathrm{e}}
$$

The signal obtained by this technique displays the evolution of the sample conductivity, I(t), (denominated photoconductivity) as a function of time (ns). The main data provided by TRMC are given by the maximum value of the signal $\left(I_{\max }\right)$, which reflects the number of the excess charge-carriers created by the laser pulse, and the decay is due to the decrease of the excess electrons (free electrons) [23,24]. To analyze the decay, the signal is divided in two sections: short- and long-range decays. The short-range decay, arbitrarily fixed up to $40 \mathrm{~ns}$ after the maximum of the pulse, is represented by the $\mathrm{I}_{40 \text { ns }} / \mathrm{I}_{\max }$ ratio, which reflects the fast processes active during and just after the pulse. Most probably electron-hole recombination and possibly electron scavenging by metal are responsible for this ratio. The long-range decay, here fixed from 200 until $1000 \mathrm{~ns}$, is related to slow processes involving trapped species, i.e., interfacial charge transfer reactions and decay of excess electrons controlled by the relaxation time of trapped holes. In this range, the decay of TRMC signal can be fitted to a power decay according to:

$$
I=I_{D} t^{-k D}
$$

where $I_{D}$ is the intensity of the signal due to charge-carriers that recombine after $200 \mathrm{~ns}$, and $k_{D}$ is an adimensional parameter related to their lifetime: higher $k_{D}$ values correspond to faster decays of the TRMC signal.

The influence of the different excitation wavelengths in charge-carrier generations was study for both bare titania and modified samples $(0.5 \mathrm{at} \%)$. The range of the wavelengths examined was from 310 to $505 \mathrm{~nm}$. The wavelengths and their corresponding excitation energies are shown in SI.2. 
The laser energy delivered in a single pulse was measured using a pyroelectric energy sensor (ES111C, Thorlabs) connected to a power meter (PM100D, Thorlabs). The numbers of incident photons in the sample, expressed as nanomole of photons also called nanoEinstein (nano-ein), were calculated by the following equation:

$$
n_{h v}=\frac{E \cdot \lambda}{h \cdot c \cdot N_{A}}
$$

where $E$ is the excitation energy (J), $\lambda$ is the wavelength (nm), $h$ is the Planck constant (J.s), $c$ the speed of light $(\mathrm{m} / \mathrm{s})$ and $\mathrm{N}_{\mathrm{A}}$ the Avogadro constant $\left(\mathrm{mol}^{-1}\right) . I_{\text {max }} / n_{h v}$ values for each wavelength were plotted. The obtained graphic is called "TRMC action spectra".

\subsection{Hydrogen production evaluation}

\subsubsection{Irradiation system under UV-visible light}

The hydrogen production was also evaluated employing a mercury lamp, which emits a whole light spectrum with a maximum intensity of UV light. Two distinct set-ups were used: (1) continuous, and (2) batch. In the first one, the production of hydrogen was followed by mass spectrometry, while in the second one, it was measured by gas chromatography.

For the "continuous" set-up, the reaction volume was $60 \mathrm{~mL}$ of a 10vol\% aqueous methanol solution and the concentration of photocatalyst was $1 \mathrm{~g} / \mathrm{L}$. The irradiation time was $60 \mathrm{~min}$. The amount of $\mathrm{H}_{2}$ was measured in real-time in the headspace thanks to an UGA mass spectrometer (SRS Instruments). The UGA is based on residual gas analyzer (RGA SRS Instrument - mass domain 1-300). The instrument is adapted for analysis at atmospheric pressure. The headspace gas of the reactor is pumped through a 1-m long capillary (peek tubing, $0.18 \mathrm{~mm} \mathrm{ID)} \mathrm{thanks} \mathrm{to} \mathrm{a}$ roughing pump. A pinhole $(400 \mathrm{~nm})$ allows a small portion of the gas to be transferred to the vacuum chamber. The pressure measured at the roughing pump is circa $1.1 \mathrm{mbar}$ and the pressure in the vacuum chamber is $5.10^{-6}$ mbar. This pressure is kept constant during the analysis. The measurement reproducibility is high as is shown in SI.5.

In case of the batch system, a glass reactor with a volume of $35 \mathrm{~mL}$ was employed. The photocatalyst (50 mg) was suspended in $5 \mathrm{~mL}$ of $50 \mathrm{vol} \%$ aqueous methanol. A sample of $0.2 \mathrm{~mL}$ of the headspace gas was taken every 15 min during $60 \mathrm{~min}$. The amount of hydrogen was determined using a gas chromatograph. 
In both continuous and batch systems, prior to suspension irradiation, a flux of nitrogen was introduced in the system in order to evacuate the oxygen.

\subsubsection{Action spectra measurements}

The action spectra for $\mathrm{H}_{2}$ evolution were measured on bare and modified $\mathrm{TiO}_{2}$ samples with the total metal loading of $0.5 \mathrm{at} \%$ for each of the three systems: $0.5-\mathrm{Ni} / \mathrm{TiO}_{2}, 0.5-\mathrm{Au} / \mathrm{TiO}_{2}$ and 0.5 $\mathrm{NiAu} / \mathrm{TiO}_{2}$. A 30-mg portion of the photocatalyst was added to quartz cuvette of $10.5-\mathrm{mL}$ volume containing $3 \mathrm{~mL}$ of 50vol\% aqueous methanol. Before irradiation, air was removed from the cell by nitrogen bubbling. The samples were irradiated under stirring with monochromatic light at 320, 350, 380, 410 and $440 \mathrm{~nm}( \pm 5 \mathrm{~nm})$, using a diffraction grating-type illuminator (JASCO CRM-FD) equipped with a 300-W xenon lamp (Hamamatsu Photonics C2578-02). The total time of irradiation was $60 \mathrm{~min}$, and each $20 \mathrm{~min}$ a gas sample of $0.2 \mathrm{~mL}$ was taken and monitored by gas chromatography (Shimadzu GC-8A). The apparent quantum efficiency (AQE) as a function of monochromatic wavelength was calculated as a ratio of the number of electrons used in hydrogen production to the flux of incident photons on the system, according to the stoichiometry of the reaction where 2 electrons were required.

\section{Results}

\section{1. Characterization of the samples}

$\mathrm{Au}^{\mathrm{III}}$ and $\mathrm{Ni}^{\mathrm{II}}$ ions were reduced by solvated electrons and reducing $\left(\mathrm{CH}_{3}\right)_{2} \mathrm{C}^{\circ} \mathrm{OH}$ radicals induced by solvent radiolysis. Indeed, high energy radiation ( $\gamma$-rays, X-rays, electrons or ions beams) of water leads to the formation of reactive species such as solvated electrons $\left(\mathrm{e}_{\mathrm{s}}^{-}\right)$(which are strong reducing species) and $\mathrm{H}^{*}$ and $\mathrm{HO}^{\circ}$ radicals. Oxidation by hydroxyl radical $\mathrm{HO}^{\circ}$ is avoided by addition of radical scavengers, such as 2-propanol, which yields after reactions with $\mathrm{HO}^{\circ}$ and $\mathrm{H}^{\circ}$ to a secondary reducing radical $\left(\mathrm{CH}_{3}\right)_{2} \mathrm{C}^{\circ} \mathrm{OH}$. Solvated electrons $\mathrm{e}_{\mathrm{s}}^{-}$and alcohol radicals are strong reducing agents able to reduce metal ions to lower valences and finally to metal atoms. The energy deposition throughout the solution ensures an initial homogeneous distribution of the radiolytic radicals and therefore a homogeneous reduction and nucleation $[18,25]$. 
The absorption spectra of pure and modified $\mathrm{TiO}_{2}$ are shown in the Figure 1. In addition to the characteristic ultraviolet absorption of $\mathrm{TiO}_{2}$, all the modified samples showed an absorption in the visible and near infrared regions, which varies according to the deposited metal. The samples containing only nickel show a flat absorption in the visible range. This absorption could be attributed to $\mathrm{NiO}$, which is known to absorb in this region, due to d-d transitions [26,27]. The samples containing gold show a maximum peak at 540-560 $\mathrm{nm}$ characteristic of the plasmon band of gold. This plasmon band is sensitive to the environment and the substrate. The coupling between metal NPs and $\mathrm{TiO}_{2}$ support has a high reflective index. Au/ $\mathrm{TiO}_{2}$ samples show a Localized Surface Plasmon Resonance (LSPR) at slightly longer wavelength than those of $\mathrm{NiAu} / \mathrm{TiO}_{2}$, which indicates larger sizes of gold NPs. The difference in the size gold NPs between $\mathrm{Au} / \mathrm{TiO}_{2}$ and $\mathrm{NiAu} / \mathrm{TiO}_{2}$ is also suggested by the colors of the samples. The pink/violet color exhibited by the bimetallic samples is attributed to small size particles, while purple color displayed by $\mathrm{Au} / \mathrm{TiO}_{2}$ samples reveals larger size. Similar observations between the color and gold LSPR shift on titania surface were reported by Kowalska et al. [28]. The samples 0.5 and 1$\mathrm{Au} / \mathrm{TiO}_{2}$ show larger scattering compared to $0.1-\mathrm{Au} / \mathrm{TiO}_{2}$ probably because of the larger $\mathrm{Au} \mathrm{NP}$ size. For the $\mathrm{NiAu} / \mathrm{TiO}_{2}$ samples, the plasmon absorbance increases with the metal loading. Similarly a slightly shift to shorter wavelength is observed as the metal loading increase.

On the other hand, the DRS of the modified samples show a slight shift in the band gap to longer wavelengths which could be due to oxygen vacancies generated $\mathrm{in}^{\mathrm{TiO}_{2}}$ during the synthesis

\section{Figure 1.}

Figure 2 shows a representative HRTEM images of the photocatalysts $0.1-\mathrm{Au} / \mathrm{TiO}_{2}$ (a) and $0.5-$ $\mathrm{NiAu} / \mathrm{TiO}_{2}$ (b). Polycrystalline metal NPs are deposited on $\mathrm{TiO}_{2}$. EDAX analyses show that these NPs are mainly composed of gold, however nickel signal is also observed in the $0.5-\mathrm{NiAu} / \mathrm{TiO}_{2}$ sample, SI.3. In $0.1-\mathrm{Au} / \mathrm{TiO}_{2}$, the average diameter of the gold NPs is around $18 \mathrm{~nm}$, while for $0.5-\mathrm{NiAu} / \mathrm{TiO}_{2}$, the diameter of the metal particles is below $9 \mathrm{~nm}$. This indicates that the addition of $\mathrm{Ni}$ has an influence on the growth of $\mathrm{Au}$ NPs. Gold NPs in $0.1-\mathrm{Au} / \mathrm{TiO}_{2}$ sample are at the interface of two or more $\mathrm{TiO}_{2}$ crystallites due to their large size. Similar observation has already been reported $[29,30]$. Thus, it is clear that the number of gold particles was limited and only a 
small portion of titania particles seemed to be in contact with gold particles.

EDAX analyses show $\mathrm{Ni}$ signals through the samples $x-\mathrm{NiAu} / \mathrm{TiO}_{2}$ and $x-\mathrm{Ni} / \mathrm{TiO}_{2}, \mathbf{S I} .3$. In both mono- and bimetallic photocatalysts, Ni NPs on $\mathrm{TiO}_{2}$ were quite difficult to observe by HRTEM probably because of the close atomic numbers of $\mathrm{Ni}$ and $\mathrm{Ti}$ and the small size of Ni clusters.

\section{Figure 2.}

XPS was used to analyze the chemical composition of the modified $\mathrm{TiO}_{2}$ and to probe the oxidation state of nickel and/or gold on the surface of the photocatalysts. The elements identified in the survey spectra were $\mathrm{Ti}, \mathrm{O}$ and $\mathrm{C}$ for all the samples, and $\mathrm{Ni}$ and/or $\mathrm{Au}$ for the modified photocatalysts. The $\mathrm{Au} 4 \mathrm{f}$ binding energy was measured for the samples $1-\mathrm{Au} / \mathrm{TiO}_{2}$ and 1$\mathrm{NiAu} / \mathrm{TiO}_{2}$. Both samples show peaks at $83.58 \mathrm{eV}$ and $87.18 \mathrm{eV}$, which are assigned to $\mathrm{Au} 4 \mathrm{f}_{7 / 2}$ and $\mathrm{Au} 4 \mathrm{f}_{5 / 2}$, correspondingly. The $\mathrm{Au} 4 \mathrm{f}$ signals obtained from the samples were compared with metallic gold foil ( $\mathrm{Au} 4 \mathrm{f} 7 / 2=84.0 \mathrm{eV}$ and $\mathrm{Au} 4 \mathrm{f} 7 / 2=87.7 \mathrm{eV})$ as shown in Figure 3a. We can consider that the position range of $\mathrm{Au}$ signals, is in agreement with $\mathrm{Au}(0)$ chemical state, but with a specific low binding energy (BE) position which has already been reported in the literature $[11,31,32]$. This shift can reflect the strong interaction of gold-based $\mathrm{NPs}$ with $\mathrm{TiO}_{2}$ changing their electronic environment.

The Ni 2p XPS spectra for the samples $1-\mathrm{Ni} / \mathrm{TiO}_{2}$ and $1-\mathrm{NiAu} / \mathrm{TiO}_{2}$ shown in Figure $\mathbf{3 b}$ are quite similar. In both samples, Ni $2 \mathrm{p}_{1 / 2}$ and $\mathrm{Ni} 2 \mathrm{p}_{3 / 2}$ peaks were identified at $873.4 \mathrm{eV}$ and $855.7 \mathrm{eV}$, respectively. Such binding energies are attributed to the presence of $\mathrm{Ni}(\mathrm{II})$ and the satellite signal at $861.7 \mathrm{eV}$ confirms the presence of $\mathrm{NiO}$. The fitting of the sample 1-NiAu/TiO 2 (Figure 3c) reveals also the existence of a small amount of $\mathrm{Ni}^{0}(853.3 \mathrm{eV})$. The exposition of Ni nanoclusters to air during the drying step may cause the partial oxidation of the samples and the formation of $\mathrm{NiO}$ clusters. However, XPS results indicate the presence of $\mathrm{Ni}^{0}$ proving that $\mathrm{Ni}$ clusters oxidation was not complete. The remaining amount of $\mathrm{Ni}^{0}$ is probably localized at the interface between $\mathrm{NiO}$ and $\mathrm{TiO}_{2}$. It has to be noted that $\mathrm{Ni} 2 \mathrm{p}$ signals are also negatively shifted from those observed for pure metal or oxide references, similar shift was reported by other groups [9]. 


\section{Figure 3.}

The dynamic of excess electrons in the conduction band of the photocatalysts and their recombination kinetics were studied by TRMC measurements on all the samples (bare $\mathrm{TiO}_{2}, x$ $\mathrm{Au} / \mathrm{TiO}_{2}, x-\mathrm{Ni} / \mathrm{TiO}_{2}$ and $x-\mathrm{NiAu} / \mathrm{TiO}_{2}$ ), see Figure 4. The transient photoconductivity data were displayed in double-logarithmic plots with a time scale from 0 to $1000 \mathrm{~ns}$. The TRMC data $\left(I_{\max }\right.$, $I_{40 \text { ns }}\left(I_{\text {max }}\right.$, and $k_{D}$ ) for each sample are presented in Table 1.

The modified photocatalysts show a reduction of the $I_{\max }$ values compared to bare $\mathrm{TiO}_{2}$. This decrease can be attributed to three phenomena linked to the metal deposition, and corresponding to the lost of charge-carriers during the pulse [33]: a) shield effect by NPs, b) surface recombination centers created by the synthesis method, and c) fast electron scavenge by the metal $(<10 \mathrm{~ns})$. A detailed analysis of the signal decay may help to understand the observed effect on $I_{\max }$.

The analysis is not trivial, because different effects are observed, the signal can be slowed down or accelerated by the metallic modification. Anyway, a global tendency can by drawn.

As explained in the experimental section, the decay kinetics can be divided in two parts: the short-time range from 0 to $40 \mathrm{~ns}$ and the long-time range from $200 \mathrm{~ns}$ to $1000 \mathrm{~ns}$.

Figure 4 and $I_{40 n s} / I_{\max }$ values of Table 1, characterizing the short time range, evidence that an opposite effect is observed for monometallic and bimetallic modifications. $\mathrm{All} \mathrm{Ni} / \mathrm{TiO}_{2}$ and $\mathrm{Au} / \mathrm{TiO}_{2}$ samples present a slightly slower or identical decay than bare $\mathrm{TiO}_{2}$, when a faster decay is observed for the $\mathrm{NiAu} / \mathrm{TiO}_{2}$. A slower decay indicates that the metal does not scavenge the electrons. This effect, already observed with Pt and Pd deposits [19,20], shows that the metal can help to avoid fast charge-carrier recombination, leading to longer electron lifetimes. A faster decay can be explained by a) a higher rate of recombination of charge-carriers, may be due to surface defects generated by the deposition or by b) electron scavenging by the metal.

Figure 4 and $k_{D}$ values of Table 1, characterizing the long time range, confirm mainly the tendency observed at short time range: an identical or slower decay for monometallic modification, and a faster decay for bimetallic one. This confirmation of an accelerated decay at long time range for $\mathrm{NiAu} / \mathrm{TiO}_{2}$ supports the hypothesis of electron scavenging by the metal. 
Indeed, the hypothesis of a higher rate of recombination of charge-carriers due to surface defects should not have been confirmed at long time range, because it corresponds to fast phenomena.

These TRMC measurements reveal that gold NPs in our systems are inefficient to scavenge electrons. This is probably due to the large size of gold particles. Indeed, theoretical calculations have indicated that the transfer of excited electrons from the semiconductor to the metal is practically inefficient when the size of the metal NPs is larger than $10 \mathrm{~nm}$ [34].

\section{Figure 4.}

\begin{tabular}{crcc}
\hline & $\boldsymbol{I}_{\boldsymbol{m a x}}(\boldsymbol{m} \boldsymbol{V})$ & \multicolumn{1}{c}{$\boldsymbol{I}_{40} / \boldsymbol{I}_{\boldsymbol{m a x}}$} & \multicolumn{1}{c}{$\boldsymbol{k}_{\boldsymbol{D}}$} \\
\hline $\mathrm{TiO}_{2}$ & 233 & 0.64 & 0.18 \\
$0.1-\mathrm{Au}$ & 224 & 0.63 & 0.18 \\
$0.5-\mathrm{Au}$ & 151 & 0.81 & 0.10 \\
$1-\mathrm{Au}$ & 155 & 0.77 & 0.14 \\
$0.1-\mathrm{Ni}$ & 202 & 0.63 & 0.18 \\
$0.5-\mathrm{Ni}$ & 135 & 0.74 & 0.13 \\
$1-\mathrm{Ni}$ & 158 & 0.45 & 0.19 \\
$0.1-\mathrm{NiAu}$ & 187 & 0.49 & 0.21 \\
$0.5-\mathrm{NiAu}$ & 190 & 0.58 & 0.19 \\
$1-\mathrm{NiAu}$ & 142 & 0.42 & 0.20 \\
\hline
\end{tabular}

Table 1. TRMC parameters for bare $\mathrm{TiO}_{2}$ and modified samples.

The relative errors are 5,10, and $10 \%$ for $I_{\max }$ and $I_{40} / I_{\max }$ and $k_{D}$ respectively.

\subsection{Photocatalytic hydrogen production under mercury lamp irradiation}

The hydrogen production rates from methanol solution $(50 / 50 \% \mathrm{v} / \mathrm{v})$ for each photocatalyst are presented in Figure 5a. As expected, bare $\mathrm{TiO}_{2}$ was largely inactive for the reaction because of $\mathrm{H}_{2}$ overpotential[4,5] and/or its short ability to act as a recombination center of atomic hydrogen $[8,35,36]$. Clearly, the deposition of metal NPs ( $\mathrm{Au}, \mathrm{Ni}$ or $\mathrm{Au}-\mathrm{Ni}$ ) on $\mathrm{TiO}_{2}$ surface improves the $\mathrm{H}_{2}$ production rate. It must be highlighted that even if the conditions for reactions in continuous and batch systems are different, a clear tendency is observed: the photocatalysts $\mathrm{x}-\mathrm{NiAu} / \mathrm{TiO}_{2}$ present the highest $\mathrm{H}_{2}$ production followed by $x-\mathrm{Ni} / \mathrm{TiO}_{2}$ and $x-\mathrm{Au} / \mathrm{TiO} \mathrm{O}_{2}$ samples as shown in Figure 5 and Table 2. The activity of $\mathrm{NiAu} / \mathrm{TiO}_{2}$ was evaluated at longer time, no change in the 
rate of hydrogen generation was observed after few hours of irradiation (see, SI.4)

Concerning the metal loading of the modified samples $\left(\mathrm{x}-\mathrm{Au} / \mathrm{TiO}{ }_{2}, \mathrm{x}-\mathrm{NiAu} / \mathrm{TiO}_{2}\right.$ and $\left.\mathrm{x}-\mathrm{Ni} / \mathrm{TiO}{ }_{2}\right)$, three different effects were observed. The system $\mathrm{Au} / \mathrm{TiO}_{2}$ shows a slightly increase in $\mathrm{H}_{2}$ evolution when the amount of metal increases, whereas for modified $\mathrm{TiO}_{2}$ containing $\mathrm{Ni}$, the amount of $\mathrm{H}_{2}$ does not follow the metal loading. The $x-\mathrm{NiAu} / \mathrm{TiO}_{2}$ photocatalysts show an optimal metal loading at $0.5 \%$, and the $x-\mathrm{Ni} / \mathrm{TiO}_{2}$ at $0.1 \%$ and $1 \%$. Previous studies on $\mathrm{Ag}$ and $\mathrm{Bi}$ $[21,37]$ have evidenced that the optimal amount depends on the nature of the metal NPs, but this effect remains mainly unclear.

Figure 5.

\begin{tabular}{|c|c|c|}
\hline & Gas chromatography & Mass spectrometry \\
\hline & $\begin{array}{c}\mathrm{H}_{2} \text { production rate } \\
\left(\mu \mathrm{mol} \cdot \mathrm{h}^{-1}\right)\end{array}$ & $\begin{array}{c}\mathrm{H}_{2} \text { production rate } \\
\left(\mu \mathrm{mol}^{-1} \mathrm{~h}^{-1}\right)\end{array}$ \\
\hline $\mathrm{TiO}_{2}$ & 6.2 & $<1$ \\
\hline $0.1-\mathrm{Au}$ & 29.0 & 25 \\
\hline $0.5-\mathrm{Au}$ & 31.6 & 46 \\
\hline $1-\mathrm{Au}$ & 39.2 & 78 \\
\hline $0.1-\mathrm{Ni}$ & 68.3 & 88 \\
\hline $0.5-\mathrm{Ni}$ & 58.2 & 135 \\
\hline $1-\mathrm{Ni}$ & 67.7 & 61 \\
\hline $0.1-\mathrm{NiAu}$ & 97.6 & 193 \\
\hline $0.5-\mathrm{NiAu}$ & 157.0 & 318 \\
\hline 1-NiAu & 136.4 & 284 \\
\hline
\end{tabular}

Table 2. $\mathrm{H}_{2}$ production rates with $x$ - $\mathrm{Au} / \mathrm{TiO}{ }_{2}, x-\mathrm{Ni} / \mathrm{TiO}_{2}$ and $x-\mathrm{NiAu} / \mathrm{TiO}_{2}$ samples and bare $\mathrm{TiO}{ }_{2}$ followed by gas chromatography and mass spectrometry. The reaction conditions are different for these two systems and are described in the experimental part. 


\subsection{Action spectra measurements}

To understand the $\mathrm{H}_{2}$ production enhancement for the modified samples, the photocatalytic activity as a function of the irradiation wavelength was investigated. Action spectra for the three different samples $\left(x-\mathrm{Au} / \mathrm{TiO}_{2}, x-\mathrm{NiAu} / \mathrm{TiO}_{2}\right.$ and $\left.x-\mathrm{Ni} / \mathrm{TiO}_{2}\right)$ possessing the same metal loading content of 0.5 at $\%$ were measured in the range $320-440 \mathrm{~nm}$ (with intervals of $30 \mathrm{~nm}$ ).

Figure 6 displays the AQE determined by the action spectra for each sample. The absorbance obtained by DRS, and the $I_{\max }$ /photons obtained by TRMC have also been plotted to follow the evolution with the wavelength of the three steps of the photocatalytic mechanism: photon absorption, charge-carrier creation, and chemical surface reaction.

It can be observed that the $\mathrm{AQE}$ of bare $\mathrm{TiO}_{2}$ is very weak. The action spectrum shows that the maximum amount of hydrogen is obtained at a wavelength of $350 \pm 5 \mathrm{~nm}$. It suggests that the highest density of electrons in the conduction band is obtained at this energy. This is in agreement with the TRMC results, where the highest photoconductivity was obtained under irradiation at $355 \pm 5 \mathrm{~nm}$.

Detailed analysis of AQE spectra of the three modified compounds suggests appreciable differences among them; the action spectrum of $0.5-\mathrm{Au} / \mathrm{TiO}{ }_{2}$ shows a low level and a maximum at $380 \mathrm{~nm}$, while the action spectra of compounds containing Ni present higher levels and follow the absorption spectra. $0.5-\mathrm{Ni} / \mathrm{TiO}_{2}$ and $0.5-\mathrm{NiAu} / \mathrm{TiO}_{2}$ samples show similar profiles, but an enhancement of the AQE is clearly shown for $0.5-\mathrm{NiAu} / \mathrm{TiO}_{2}$. Considering the small amount of gold, the enhancement in $\mathrm{H}_{2}$ production cannot be explained only by an additional effect of gold, but by a synergistic effect of gold with nickel.

P25 is a mixture of anatase (main) and rutile with absorption edge at 380 and $410 \mathrm{~nm}$, respectively. Thereby a shoulder of its absorption spectrum at ca. $400 \mathrm{~nm}$ is assigned to rutile phase. The observed action spectra of modified compounds suggest that gold and nickel particles were loaded predominantly on rutile, and anatase particle, respectively. It has been reported that platinum particles were photodeposited preferentially on rutile in P25 if the number of platinum particles was small and the corresponding action spectrum showed a dip in the wavelength region at around $350 \mathrm{~nm}[38,39]$. This was explained by the disturbance of rutile photoabsorption by inactive anatase crystallites in the relatively short wavelength region. Thus, anatase and rutile 
crystallites mainly work in $0.5-\mathrm{Ni} / \mathrm{TiO}_{2}$ and $0.5-\mathrm{Au} / \mathrm{TiO}_{2}$, respectively, even though both crystallites absorb light, and $0.5-\mathrm{NiAu} / \mathrm{TiO}_{2}$ might show activity higher than the sum of activities of singly modified samples due to both crystallites work effectively.

For the bare $\mathrm{TiO}_{2}$, the low AQE values are associated to high TRMC signal. In comparison, modified compounds present higher AQE values corresponding to slightly lower TRMC signal. This point confirms the assumption that the positive effect of the NPs is more effective on the $\mathrm{H}_{2}$ overpotential, i.e. its ability to act as a recombination center of atomic hydrogen, than on the separation of charge-carriers.

\section{Figure 6.}

\section{Discussion}

According to the TRMC results, the metal loading on the surface of $\mathrm{TiO}_{2}$ have a different influence on the electronic properties of $\mathrm{TiO}_{2}$. For nickel-gold/ $/ \mathrm{TiO}_{2}$ samples, a very small transfer of photoelectron to metal was observed, while for gold/ $\mathrm{TiO}_{2}$ samples, no electron transfer from the metal to $\mathrm{TiO}_{2}$ was observed. Surprisingly, however all the modified samples show enhanced hydrogen production, in increasing order from $x-\mathrm{Au} / \mathrm{TiO}, x-\mathrm{Ni} / \mathrm{TiO}_{2}$ and $x-\mathrm{NiAu} / \mathrm{TiO}$. The results evidence that the role of the metal is not only to avoid the recombination of chargecarriers by trapping electrons [4,5], but also to act as recombination center of atomic hydrogen $\left(\mathrm{H}^{\bullet}\right)$ coming from $\mathrm{TiO}_{2}$ surface to form hydrogen, as it has been recently proposed [8].

Both theoretical and experimental results demonstrate that $\mathrm{TiO}_{2}$ can reduce the protons $\left(\mathrm{H}^{+}\right)$to atomic hydrogen, however $\mathrm{TiO}_{2}$ surface is not capable to act an efficient recombination center of $\mathrm{H}^{\bullet}[8,36]$. In this context and considering the results obtained in this work, we propose a photocatalytic mechanism for each system.

It is well known that a Schottky contact is formed between $\mathrm{Au}$ and $\mathrm{TiO}_{2}$, where the electron transfer depends on the size of metal NPs: for example small metal particles improve the electron transfer and vice versa $[34,40]$. The HRTEM study for $\mathrm{Au} / \mathrm{TiO}_{2}$ photocatalysts reveals a large average particle size (mean size $18 \mathrm{~nm}$ ), such a size is too large to scavenge photoexcited electrons $[30,34,40]$. TRMC results support the idea of negligible electron scavenging by Au NPs in $x$ - $\mathrm{Au} / \mathrm{TiO}_{2}$ samples. $\mathrm{H}_{2}$ production by $\mathrm{Au} / \mathrm{TiO}_{2}$ photocatalysts can be explained by the facts 
that $\mathrm{Au}$ NPs decrease the electron-hole recombination and act as recombination centers of atomic hydrogen $\left(\mathrm{H}^{\bullet}\right)$ coming from $\mathrm{TiO}_{2}$ surface as is shown in the Figure 7.

\section{Figure 7.}

For $\mathrm{Ni} / \mathrm{TiO}_{2}$ samples, most of the nickel is dispersed as small $\mathrm{NiO}$ clusters on the semiconductor surface. This composite $\mathrm{Ni}^{0}-\mathrm{NiO}$ will be written $\mathrm{Ni}(\mathrm{O})$ further. In order to find out the photocatalytic role of nickel species deposed on $\mathrm{TiO}_{2}$, a series of hypotheses are discussed. Firstly, the $\mathrm{NiO} / \mathrm{TiO}_{2}$ junction hypothesis is disregarded, because of the position conduction band energy level of $\mathrm{NiO}$ is higher than of that of $\mathrm{TiO}_{2}$ [41], then electron transfer from $\mathrm{TiO}_{2}$ to $\mathrm{NiO}$ is not probable. Another, possibility is that $\mathrm{NiO}$ acts as active sites for $\mathrm{H}^{\bullet}$ recombination. This may explain the formation of hydrogen. However, it is worth mentioning that in our samples a small amount of $\mathrm{Ni}^{0}$ is also present. Because of the high reactivity of metallic nickel with air, it is expected that the remaining $\mathrm{Ni}^{0}$ (detected by XPS) is located between the interphase of $\mathrm{TiO}_{2}$ and $\mathrm{NiO}$ clusters. It has been reported that a $\mathrm{Ni}(\mathrm{O})$ deposited on a semiconductor has a higher photocatalytic activity for water splitting than the single components [10]. The latter evidence shows the importance of $\mathrm{Ni}^{0}$ in the sample. It is well known that $\mathrm{Ni}$ forms an ohmic junction with $\mathrm{TiO}_{2}$, through which the photo-excited electrons migrate to the metal. In our samples the $\mathrm{Ni}^{0}$ amount is small, therefore the electrons transfer should be small.

In addition, TRMC signals and action spectra suggest that both $\mathrm{NiO}$ and $\mathrm{TiO}_{2}$ are photoexcited simultaneously under UV-light irradiation. Based on our observations, we propose a scheme for $\mathrm{Ni} / \mathrm{TiO}_{2}$ that explains its photocatalytic activity, see Figure 8. The photons absorption induces excitation of both $\mathrm{TiO}_{2}$ and $\mathrm{NiO}$. The oxidative part (protons formation, $\mathrm{H}^{+}$) is carried out only in the valence band of $\mathrm{TiO}_{2}$, while the reduction of protons is carried out in both conduction bands of $\mathrm{NiO}$ and $\mathrm{TiO}_{2}$ semiconductors. $\mathrm{H}_{2}$ production (hydrogen atomic recombination) takes place only on $\mathrm{NiO}$ surface. The $\mathrm{TiO}_{2}$ electrons transferred by $\mathrm{Ni}^{0}$ ohmic contact recombine with the holes of NiO. Thus, the amount of photoexcited electrons is identical to that of bare $\mathrm{TiO}_{2}$, this idea is supported by TRMC results, which show an identical decay for $x-\mathrm{Ni} / \mathrm{TiO}_{2}$ and bare $\mathrm{TiO}_{2}$. The advantage of an ohmic contact in the photocatalyst is a larger number of holes available in the valence band of $\mathrm{TiO}_{2}$. 


\section{Figure 8.}

Finally for the $\mathrm{NiAu} / \mathrm{TiO}_{2}$ samples, an alloy is not expected because of the immiscibility between nickel and gold $[42,43]$. The characterization of the samples confirms the metal segregation. On TRMC, the $\mathrm{NiAu} / \mathrm{TiO}_{2}$ samples exhibit a change in the charge-carrier kinetics attributed to electrons scavenging by the metals. However, that change is not evident suggesting that only a small amount of electrons are trapped. The decrease of gold particle size, as evidenced by HRTEM results, is probably the cause of electron scavenging improvement. The Au loading in $\mathrm{NiAu} / \mathrm{TiO}_{2}$ samples is five times slower than the $\mathrm{Ni}$ loading. The hydrogen generation improvement cannot be attributed only to small amount of gold.

The $x-\mathrm{NiAu} / \mathrm{TiO}_{2}$ samples are much more efficient in photocatalytic hydrogen generation than the monometallic samples. For example, in the batch system the rate of generated hydrogen using $x-\mathrm{Ni} / \mathrm{TiO}_{2}$ and $x-\mathrm{Au} / \mathrm{TiO}_{2}$ were 31 and $58 \mu$ mol.h ${ }^{-1}$ respectively, while the sample $x-\mathrm{NiAu} / \mathrm{TiO}_{2}$, under the same conditions, reaches an $\mathrm{H}_{2}$ rate of $157 \mu$ mol.h ${ }^{-1}$. Clearly, the improvement of the photocatalytic performance was due to a synergetic effect between $\mathrm{Au}$ and $\mathrm{Ni}(\mathrm{O})$ since it was not a simple additive effect.

The synergetic effect has been observed using bimetallic NPs in catalysis and photocatalysis [4446]. In photocatalysis, the synergy has been commonly related to electronic and geometry effects. However, further experiments are needed to deeply understand the origin of this synergetic effect.

Based on our experimental results, we propose a reaction scheme for hydrogen photoproduction on $x-\mathrm{NiAu} / \mathrm{TiO}_{2}$ samples (Figure 9). The mechanism is similar to that proposed for $x-\mathrm{Ni} / \mathrm{TiO}_{2}$. The generation of the electron-hole pair takes place on the $\mathrm{TiO}_{2}$ and $\mathrm{NiO}$ surfaces. The holes, coming from $\mathrm{TiO}_{2}$, oxidize water and/or the methanol mixture generating protons, which are then reduced at the surface of both $\mathrm{TiO}_{2}$ and $\mathrm{NiO}$ forming atomic hydrogen. Finally, $\mathrm{H}^{\bullet}$ recombination occurs on the surface of metal NPs forming $\mathrm{H}_{2}$. The improvement of hydrogen generation compared with that of the monometallic samples is attributed to a synergetic effect between both $\mathrm{Ni}(\mathrm{O})$ and $\mathrm{Au}$ acting as a better atomic hydrogen recombination site than the monometallic samples. 
According to a recent review on supported model catalysts [47], the catalytic activity depends mainly on the size and shape of the metal nanoparticles, but in some cases also on the distance between them. Therefore, despite the segregation between $\mathrm{Ni}(\mathrm{O})$ and $\mathrm{Au}$ in our co-modified samples, the proximity between $\mathrm{Au}$ and $\mathrm{Ni}$-based nanoparticles seems to be enough to act as a better active site for atomic hydrogen recombination, consequently a synergetic effect can be considered.

\section{Figure 9.}

\section{Conclusions}

$\mathrm{Ni}$ and/or $\mathrm{Au}$ NPs were synthesized on $\mathrm{P} 25 \mathrm{TiO}_{2}$ by radiolysis. According to the characterization results, a segregation of the two metals was observed. Large Au NPs and Ni nanoclusters (partially oxidized) were obtained on $\mathrm{TiO}_{2}$. The surface modification of $\mathrm{TiO}_{2}$ with $\mathrm{Ni}$ and $\mathrm{Au}$ NPs resulted in an increase of the photocatalytic activity for hydrogen production using a methanol-water solution under UV light. The highest production of hydrogen was obtained with the $\mathrm{NiAu} / \mathrm{TiO}_{2}$ catalysts, which was explained in terms of a synergetic effect by the presence on $\mathrm{Au} \mathrm{NPs}$ and $\mathrm{Ni}(\mathrm{O})$ clusters on $\mathrm{TiO}_{2}$, acting as recombination sites for atomic hydrogen conversion to molecular hydrogen.

We have found that a very small amount of gold associated to nickel (atomic ratio Ni:Au 5:1 and total metal 0.5 to 1 at $\%$ ) can induce a significant increase in $\mathrm{H}_{2}$ formation, thus the costs of photocatalyst preparation are relatively low. These bimetallic NPs can also have applications in catalysis and electrocatalysis.

\section{Acknowledgements:}

Financial support from the CNRS and CONCERT-Japan Joint Call on Efficient Energy Storage (CNRS France, JST Japan, DLR Germany) are highly acknowledged. Ana L. Luna acknowledges CONACYT for the PhD Scholarship. Miguel A. Valenzuela gratefully acknowledges the financial support of the CONACYT projects \#153356 and \#252003. The authors acknowledge also C'Nano Ile de France for the financial support for the gamma source and for TRMC setup. 
The RTRA Triangle de la Physique and the ANR project PhotoNorm are also acknowledged for the TRMC setup.

\section{References}

[1] G.L. Chiarello, M.H. Aguirre, E. Selli, J. Catal. 273 (2010) 182-190.

[2] Á. Valdés, J. Brillet, M. Grätzel, H. Gudmundsdóttir, H. a. Hansen, H. Jónsson, P. Klüpfel, G.-J. Kroes, F. Le Formal, I.C. Man, R.S. Martins, J.K. Nørskov, J. Rossmeisl, K. Sivula, A. Vojvodic, M. Zäch, Phys. Chem. Chem. Phys. 14 (2012) 49-70.

[3] H. Bahruji, M. Bowker, P.R. Davies, L.S. Al-Mazroai, A. Dickinson, J. Greaves, D. James, L. Millard, F. Pedrono, J. Photochem. Photobiol. A Chem. 216 (2010) 115-118.

[4] A. a. Ismail, D.W. Bahnemann, Sol. Energy Mater. Sol. Cells 128 (2014) 85-101.

[5] J. Schneider, M. Matsuoka, M. Takeuchi, J. Zhang, Y. Horiuchi, M. Anpo, D.W. Bahnemann, (2014).

[6] J. Disdier, J.-M. Herrmann, P. Pichat, J. Chem. Soc. Faraday Trans. 79 (1983) 651-660.

[7] P. V Kamat, J. Phys. Chem. Lett. 3 (2012) 663-672.

[8] J.B. Joo, R. Dillon, I. Lee, Y. Yin, C.J. Bardeen, F. Zaera, Proc. Natl. Acad. Sci. 111 (2014) 7942 7947.

[9] W.-T. Chen, A. Chan, D. Sun-Waterhouse, T. Moriga, H. Idriss, G.I.N. Waterhouse, J. Catal. 326 (2015) 43-53.

[10] K. Domen, A. Kudo, T. Onishi, N. Kosugi, H. Kuroda, J. Phys. Chem. 90 (1986) 292-295.

[11] Z. Hai, N. El Kolli, D.B. Uribe, P. Beaunier, M. José-Yacaman, J. Vigneron, A. Etcheberry, S. Sorgues, C. Colbeau-Justin, J. Chen, H. Remita, J. Mater. Chem. A 1 (2013) 10829.

[12] S.W. Verbruggen, M. Keulemans, M. Filippousi, D. Flahaut, G. Van Tendeloo, S. Lacombe, J. a. Martens, S. Lenaerts, Appl. Catal. B Environ. 156-157 (2014) 116-121.

[13] Y. Qu, X. Duan, Chem. Soc. Rev. 42 (2013) 2568-2580.

[14] C.-J. Wang, Y. Chen, X.-J. Lv, W.-F. Fu, Appl. Catal. B Environ. 182 (2016) 59-67.

[15] Y. Zhao, F. Pan, H. Li, G.Q. Xu, W. Chen, ChemCatChem 6 (2014) 454-458.

[16] M. Cheng, M. Zhu, Y. Du, P. Yang, Int. J. Hydrogen Energy 38 (2013) 8631-8638.

[17] S. Oros-Ruiz, R. Zanella, S.E. Collins, A. Hernández-Gordillo, R. Gómez, Catal. Commun. 47 (2014) 1-6.

[18] J. Belloni, M. Mostafavi, H. Remita, J. Marignier, and M.-O. Delcourt, New J. Chem. 22 (1998) 1239-1255.

[19] O. Tahiri Alaoui, A. Herissan, C. Le Quoc, M.E.M. Zekri, S. Sorgues, H. Remita, C. ColbeauJustin, J. Photochem. Photobiol. A Chem. 242 (2012) 34-43.

[20] E. Kowalska, H. Remita, C. Colbeau-Justin, J. Hupka, J. Belloni, J. Phys. Chem. C 112 (2008) 1124-1131.

[21] E. Grabowska, A. Zaleska, S. Sorgues, M. Kunst, a. Etcheberry, C. Colbeau-Justin, H. Remita, J. Phys. Chem. C 117 (2013) 1955-1962. 
[22] S. Chettibi, N. Keghouche, Y. Benguedouar, M.M. Bettahar, J. Belloni, Catal. Letters 143 (2013) 1166-1174.

[23] M. Kunst, G. Beck, J. Appl. Phys. 60 (1986) 3558.

[24] C. Colbeau-Justin, M. Kunst, D. Huguenin, J. Mater. Sci. 38 (2003) 2429-2437.

[25] S. Remita and H. Remita, in:, Recent Trends Radiat. Chem., 2010, pp. 347-387.

[26] C.-C. Hu, H. Teng, J. Catal. 272 (2010) 1-8.

[27] N. Guillou, C. Livage, G. Férey, Eur. J. Inorg. Chem. (2006) 4963-4978.

[28] E. Kowalska, R. Abe, B. Ohtani, Chem. Commun. (2009) 241-243.

[29] D. Tsukamoto, Y. Shiraishi, Y. Sugano, S. Ichikawa, S. Tanaka, T. Hirai, (2012).

[30] M. Murdoch, G.I.N. Waterhouse, M. a Nadeem, J.B. Metson, M. a Keane, R.F. Howe, J. Llorca, H. Idriss, Nat. Chem. 3 (2011) 489-492.

[31] R.J. Chimentão, F. Medina, J.L.G. Fierro, J. Llorca, J.E. Sueiras, Y. Cesteros, P. Salagre, J. Mol. Catal. A Chem. 274 (2007) 159-168.

[32] M. Tominaga, Y. Taema, I. Taniguchi, J. Electroanal. Chem. 624 (2008) 1-8.

[33] C.A. Emilio, M.I. Litter, M. Kunst, M. Bouchard, C. Colbeau-Justin, Langmuir 22 (2006) 36063613.

[34] T. Ioannides, X. Verykios, J. Catal. 569 (1996) 560-569.

[35] R. Baba, S. Nakabayashi, A. Fujishima, K. Honda, J. Phys. Chem. 89 (1985) 1902-1905.

[36] M.M. Islam, M. Calatayud, G. Pacchioni, J. Phys. Chem. C 115 (2011) 6809-6814.

[37] N.A. Kouamé, O.T. Alaoui, A. Herissan, E. Larios, M. José-Yacaman, A. Etcheberry, C. ColbeauJustin, H. Remita, New J. Chem. 39 (2015) 2316-2322.

[38] B. Ohtani, K. Wang, E. Kowalska, in:, Abstr. Proc. First Int. Symp. Recent Prog. Energy Environ. Photocatal., Tokyo, Japan, 2015, p. 12.

[39] B. Ohtani, O.O. Prieto-Mahaney, D. Li, R. Abe, J. Photochem. Photobiol. A Chem. 216 (2010) 179-182.

[40] V. Subramanian, E.E. Wolf, P. V Kamat, J. Am. Chem. Soc. 126 (2004) 4943-50.

[41] H.-L. Yip, A.K.-Y. Jen, Energy Environ. Sci. 5 (2012) 5994.

[42] S. Zhou, Z. Ma, H. Yin, Z. Wu, B. Eichhorn, S.H. Overbury, S. Dai, J. Phys. Chem. C 113 (2009) 5758-5765.

[43] R. Ferrando, J. Jellinek, R.L. Johnston, Chem. Rev. 108 (2008) 845-910.

[44] R.P. Doherty, J.-M. Krafft, C. Méthivier, S. Casale, H. Remita, C. Louis, C. Thomas, J. Catal. 287 (2012) 102-113.

[45] A. Zielinska-jurek, J. Nanomater. 2014 (2014).

[46] H. Cao, Z. Fan, G. Hou, Y. Tang, G. Zheng, Electrochim. Acta 125 (2014) 275-281.

[47] C.R. Henry, Catal. Letters 145 (2015) 731-749. 


\section{Figure captions}

Figure 1. UV-Vis absorbance spectra of bare and modified $\mathrm{TiO}_{2}$ : (a) $x-\mathrm{Ni} / \mathrm{TiO}_{2}$; (b) $x-\mathrm{Au} / \mathrm{TiO}_{2}$; and (c) $x-\mathrm{NiAu} / \mathrm{TiO}_{2}(\mathrm{x}=0.1,0.5$ and 1$)$.

Figure 2. HRTEM images for: (a) $0.1-\mathrm{Au} / \mathrm{TiO}_{2}$ and (b) $0.5-\mathrm{NiAu} / \mathrm{TiO}_{2}$.

Figure 3. XPS spectra of modified samples with metal loading of 1at\%: (a) Au $4 \mathrm{f}$ core-level for $\mathrm{Au}^{0}$ reference and the samples modified with $\mathrm{Au}$; (b) $\mathrm{Ni} 2 \mathrm{p}$ spectra of $\mathrm{Ni}^{0}$ and $\mathrm{NiO}$ references, and $\mathrm{TiO}_{2}$ modified samples with $\mathrm{Ni}$; and (c) Curve fitting for sample 1-NiAu/TiO 2 .

Figure 4. TRMC signal of modified samples and bare $\mathrm{TiO}_{2}$ induced by $355 \mathrm{~nm}$ light pulses at $747 \mu \mathrm{J} . \mathrm{cm}^{-2}$ excitation density: (a) $x-\mathrm{Ni} / \mathrm{TiO}_{2}$; (b) $x-\mathrm{Au} / \mathrm{TiO}_{2}$; and (c) $x-\mathrm{NiAu} / \mathrm{TiO}_{2}$.

Figure 5. $\mathrm{H}_{2}$ photoproduction from methanol solution under UV light: (a) $\mathrm{R}_{\mathrm{H} 2}$ (from 50vol\% aqueous methanol solution) measured by gas chromatography; and (b) Continuous profile of $\mathrm{H}_{2}$ generation using modified samples 0.5 at $\%$ in metal (from 10vol\% aqueous methanol) measured by mass spectrometry. The relative errors are $3 \%$. The reaction conditions are different for those two systems and are described in the experimental part.

Figure 6. Absorption spectra (photon absorption), TRMC spectra (charge-carrier creation) and action spectra (apparent quantum efficiency) of modified samples, metal loading of 0.5 at\%.

Figure 7. Gold NPs acting as recombination site.

Figure 8. A Proposed mechanism of $\mathrm{H}_{2}$ production on $\mathrm{x}-\mathrm{Ni} / \mathrm{TiO}_{2}$ samples.

Figure 9. A proposed mechanism for $\mathrm{H}_{2}$ production on $\mathrm{x}-\mathrm{NiAu} / \mathrm{TiO}_{2}$ samples. 

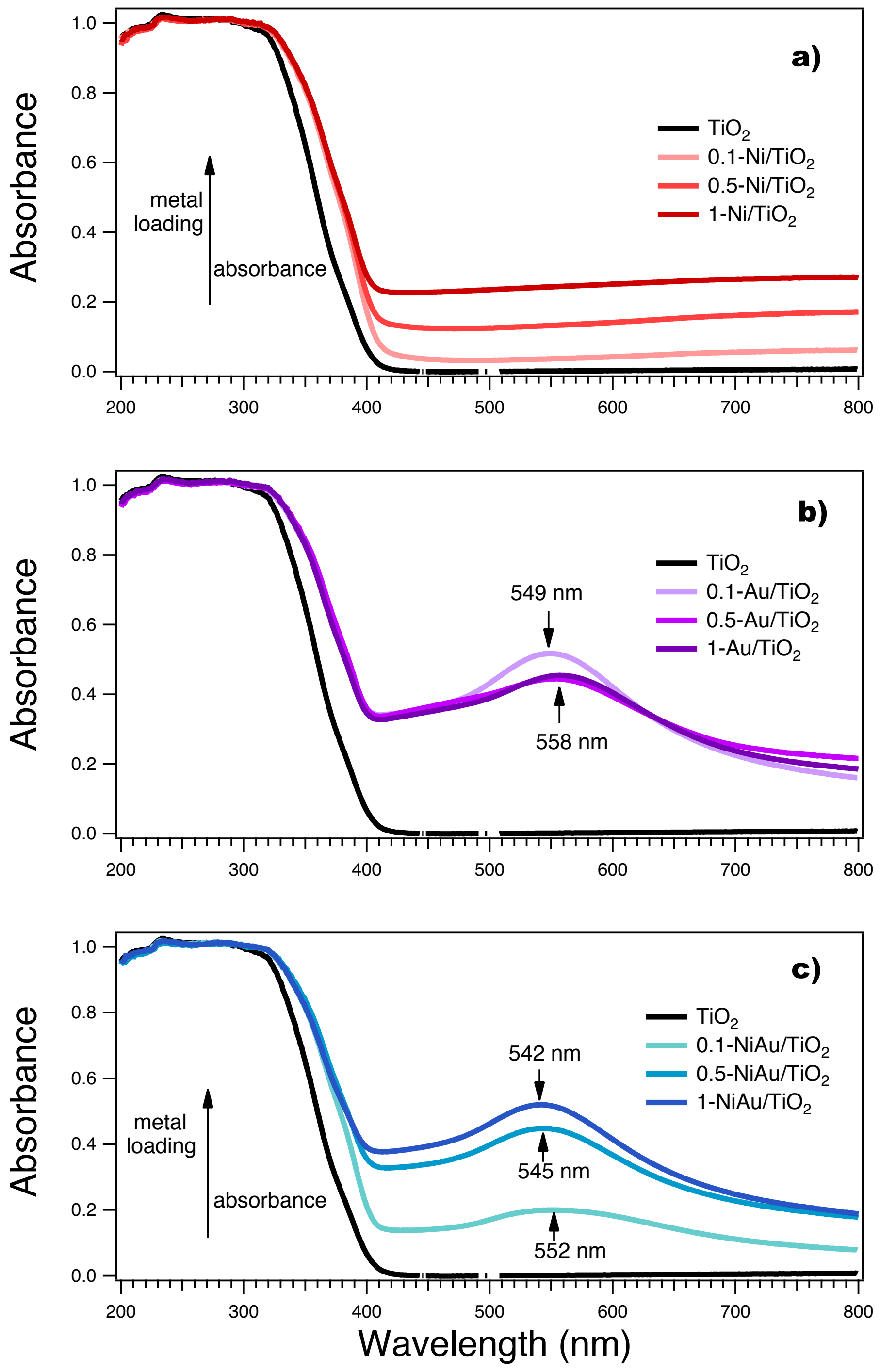

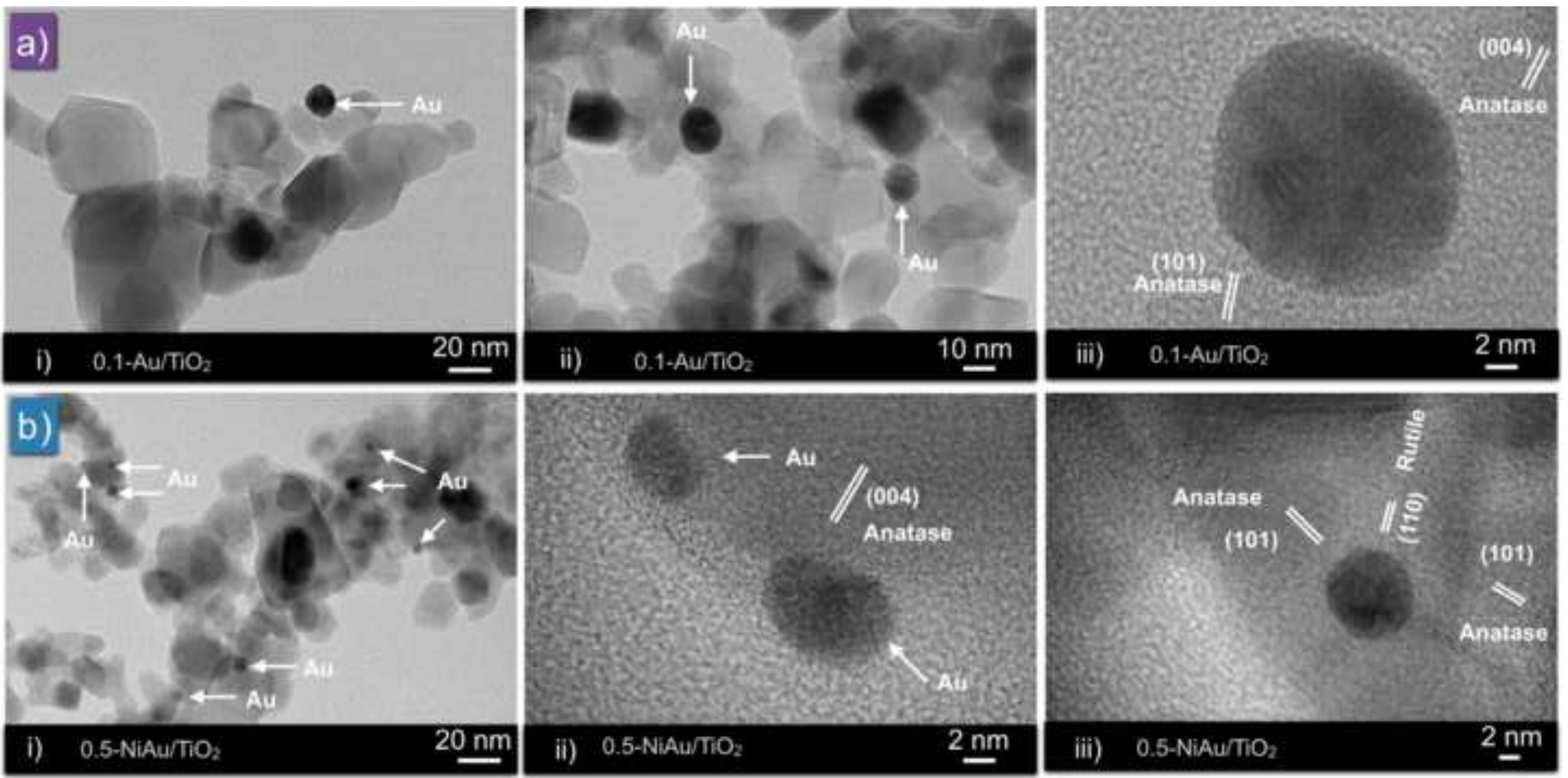

i) $0.5-\mathrm{NiAu} / \mathrm{TIO}_{2}$

ii) 0.5-NiAu/TrO;

0.5-NiAu/TiO2

- 

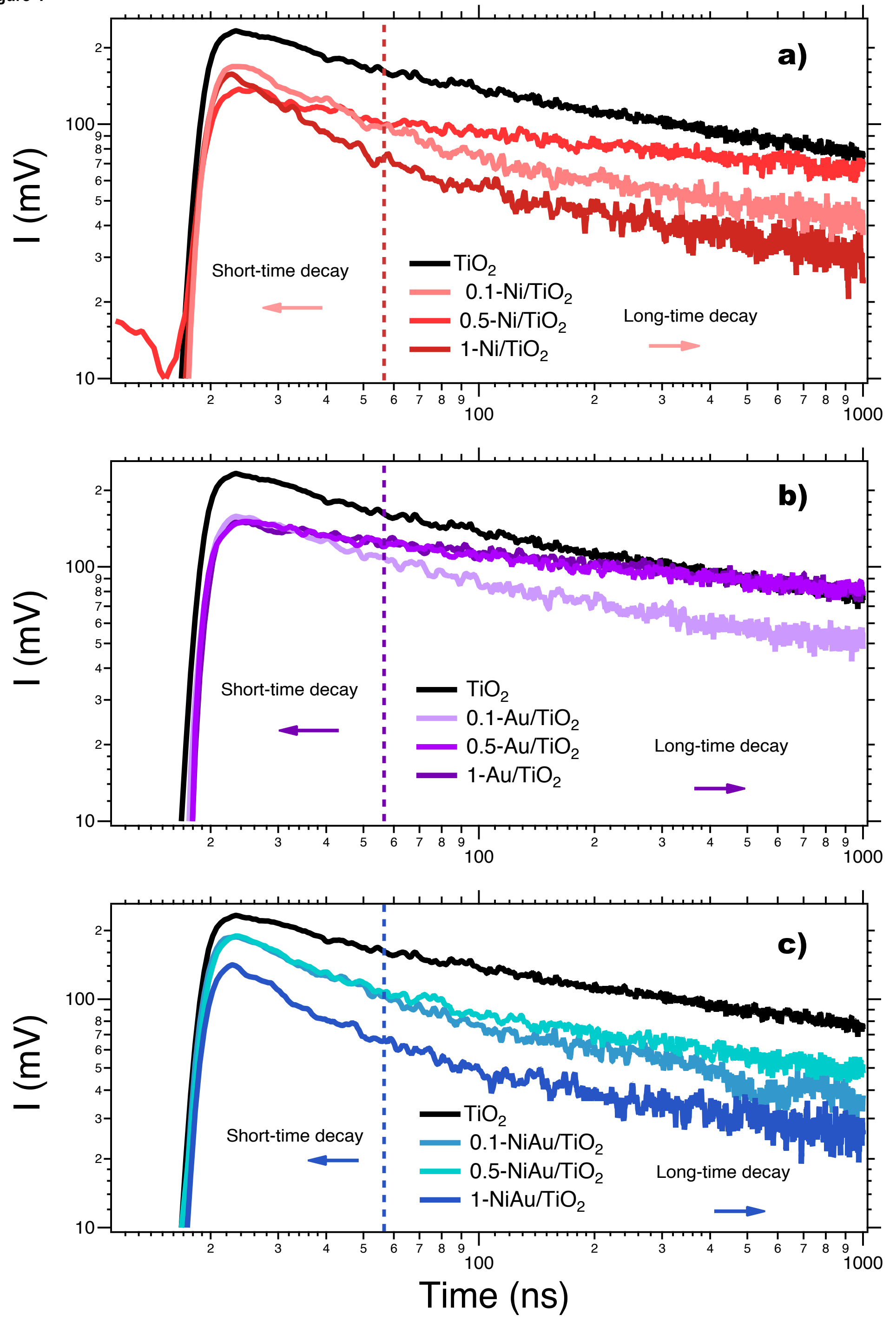


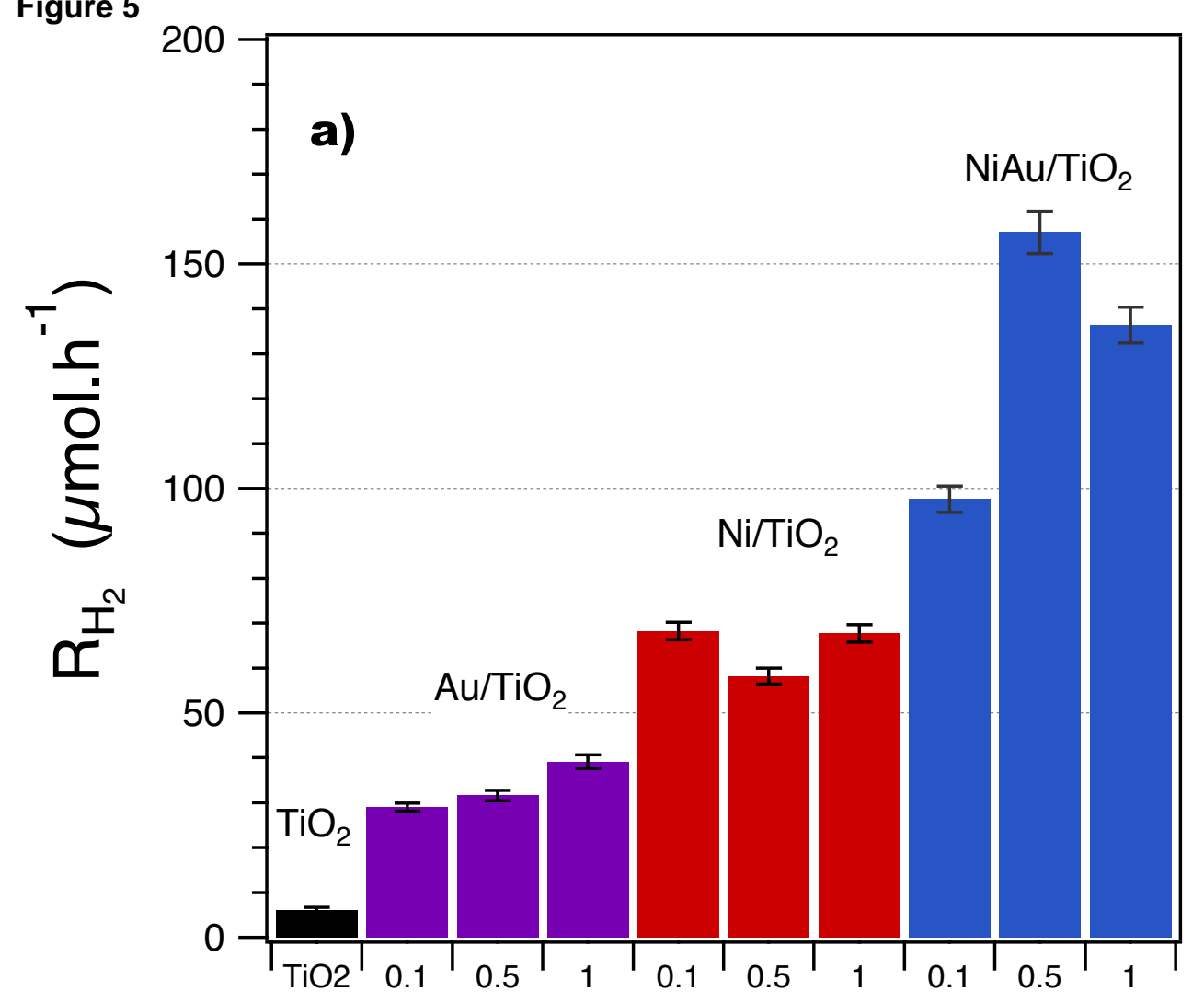

Atomic percent on $\mathrm{TiO}_{2}$ surface

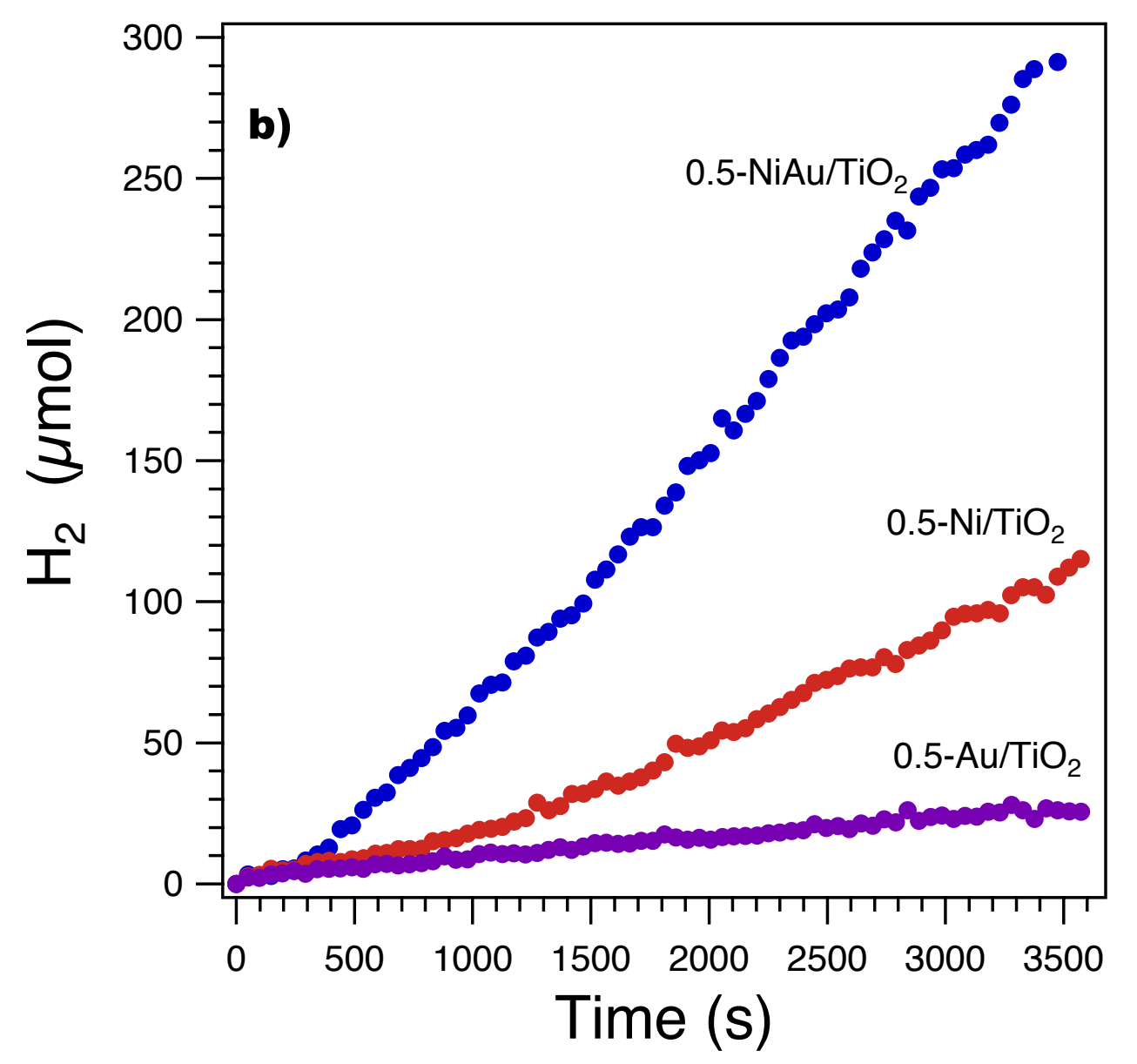




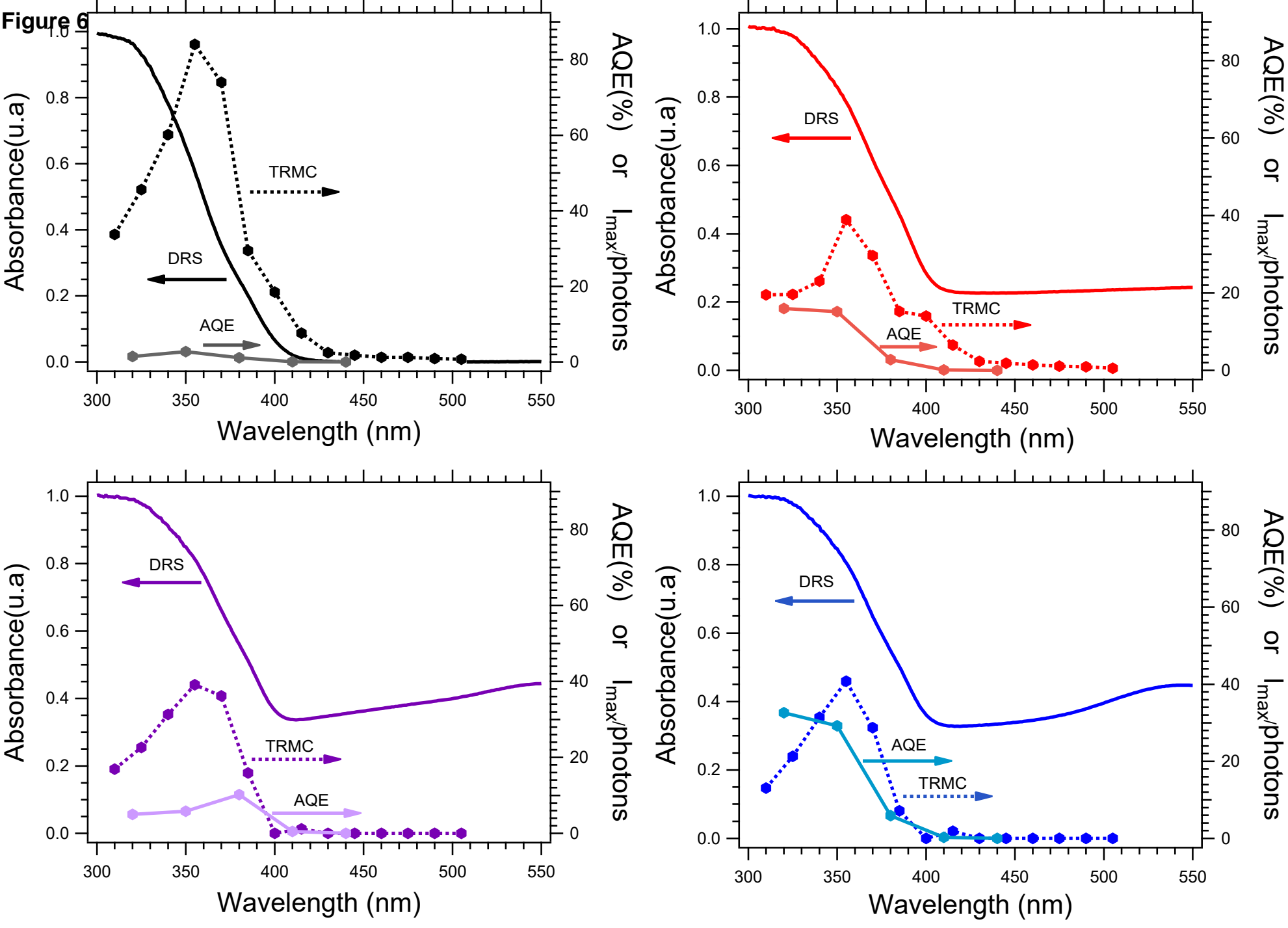




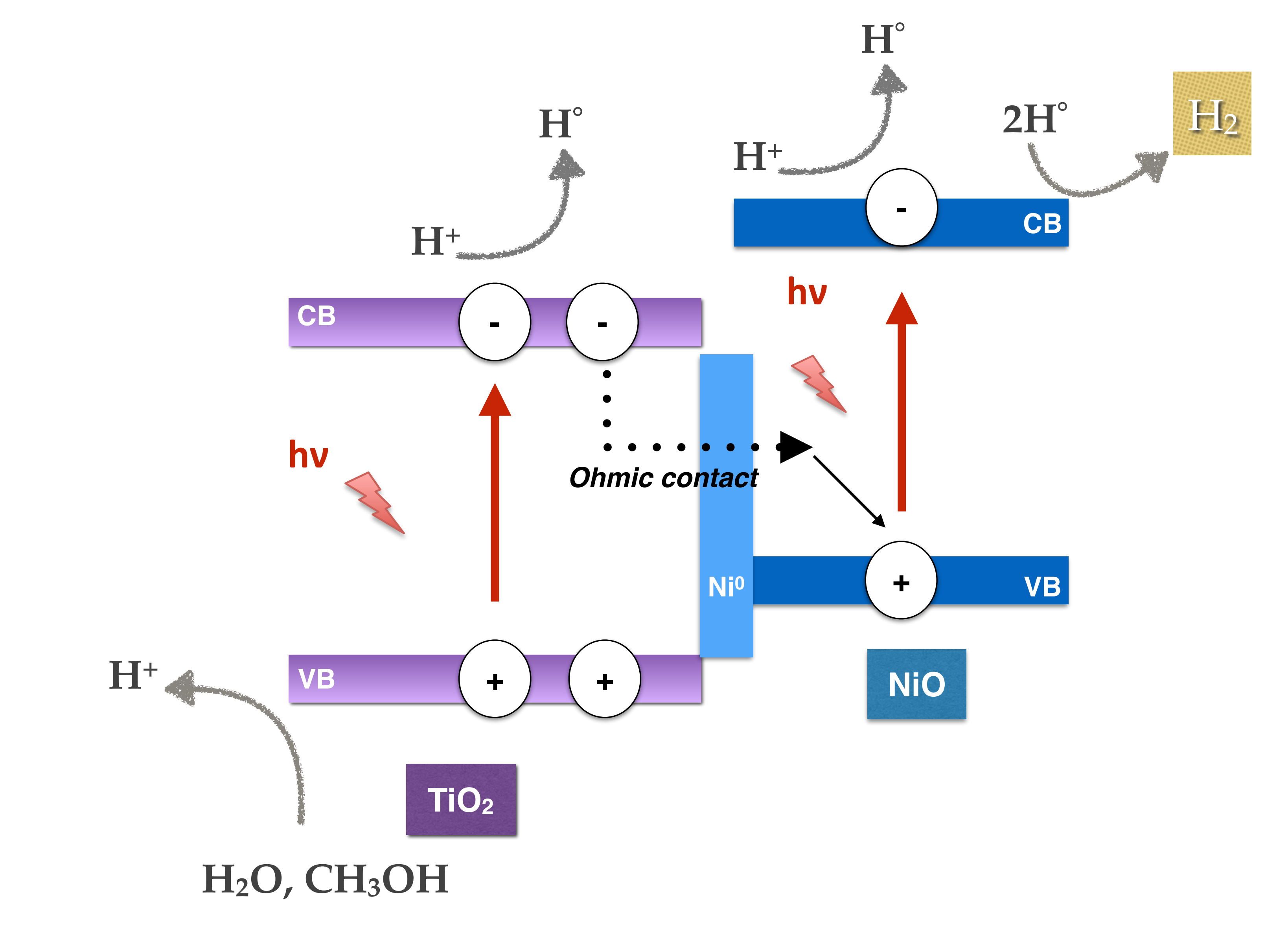

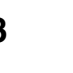




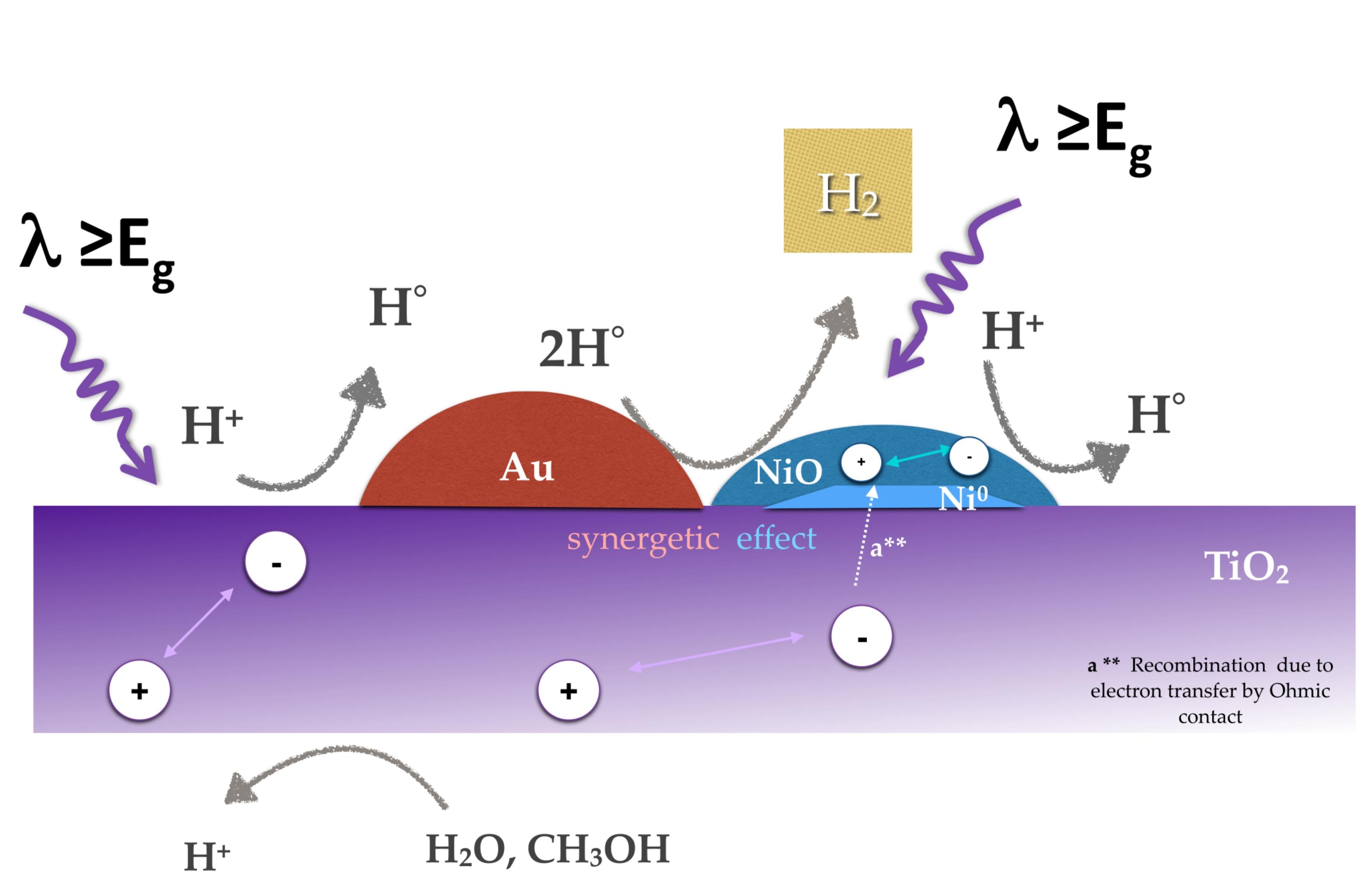

$\lambda \geq \mathrm{E}_{\mathrm{g}}$

synergetic effect

a ** Recombination due to electron transfer by Ohmic contact

$\mathbf{H}^{+}$

\author{
$\mathrm{H}_{2} \mathrm{O}, \mathrm{CH}_{3} \mathrm{OH}$
}

\title{
$\lambda \geq \mathrm{E}_{\mathrm{g}}$
}

\section{$\mathrm{TiO}_{2}$}

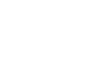

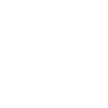

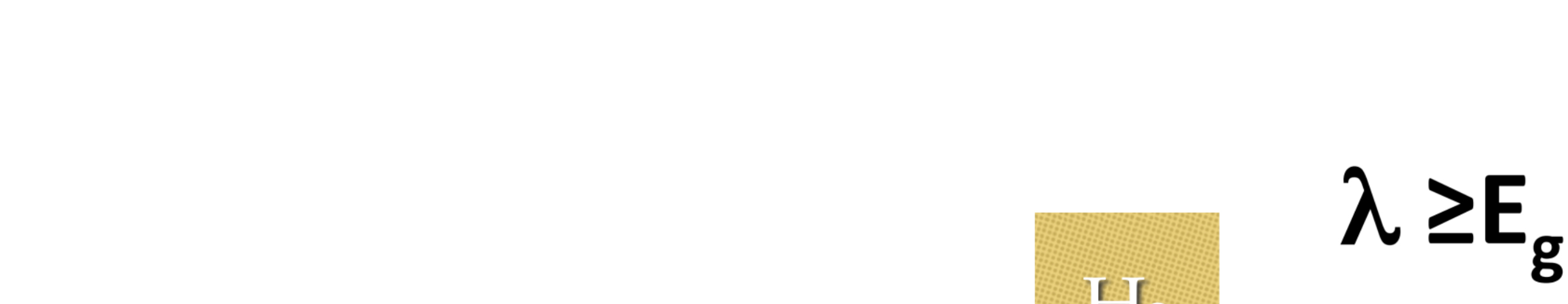

(a) 


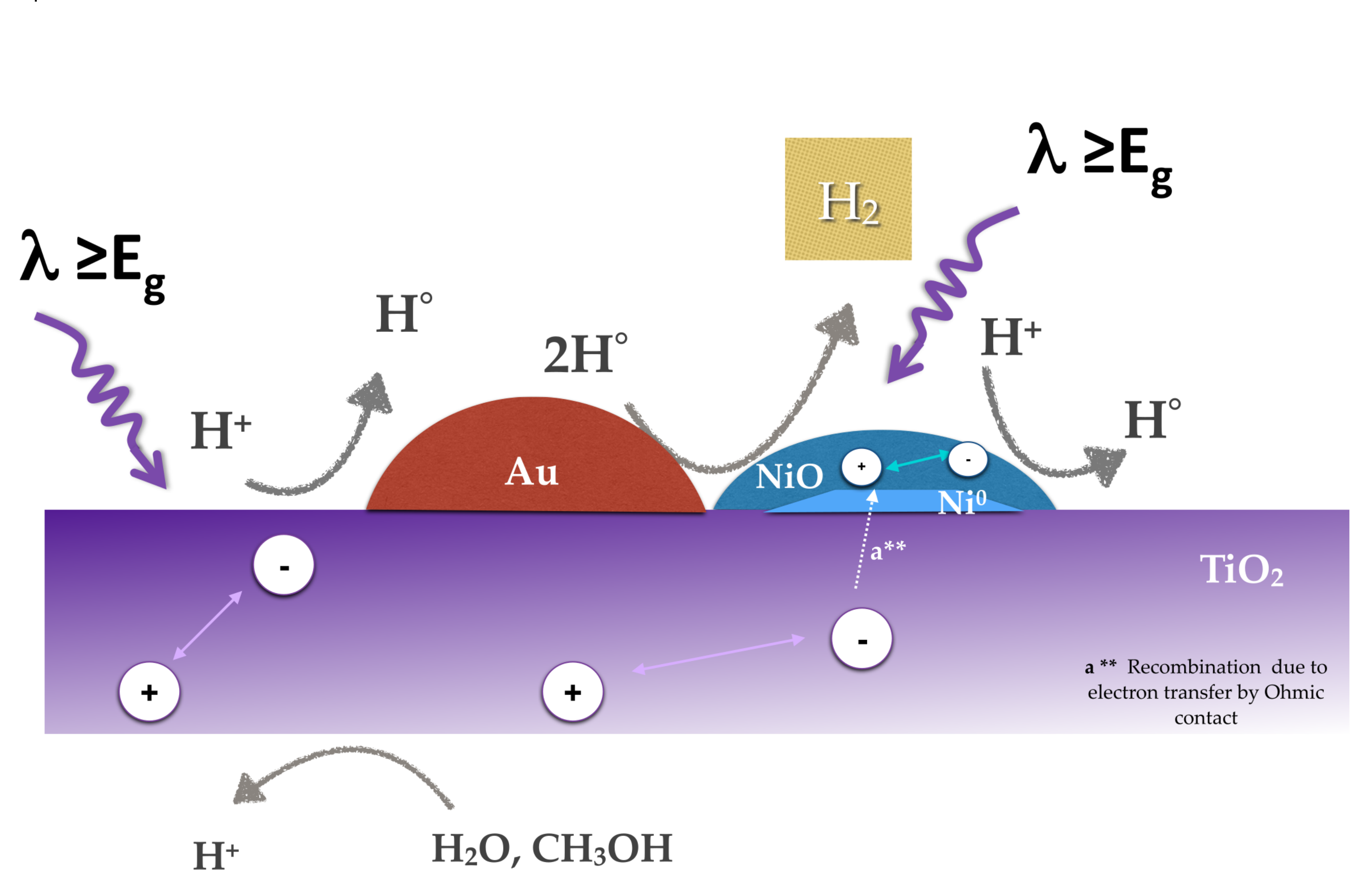

$\lambda \geq E_{g}$

$\mathrm{H}_{2} \mathrm{O}, \mathrm{CH}_{3} \mathrm{OH}$

a ** Recombination due to electron transfer by Ohmic contact

$\mathbf{H}^{+}$

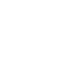

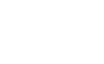

